\title{
An outreach support group for international students
}

Timothy B. Smith

Brigham Young University, tbs@byu.edu

Li-Chen Chin

University of Pennsylvania

Arpana Inman

Temple University

Jennifer Hudson

Temple University

Follow this and additional works at: https://scholarsarchive.byu.edu/facpub

Part of the Educational Sociology Commons

\section{BYU ScholarsArchive Citation}

Smith, Timothy B.; Chin, Li-Chen; Inman, Arpana; and Hudson, Jennifer, "An outreach support group for international students" (1999). Faculty Publications. 3145.

https://scholarsarchive.byu.edu/facpub/3145

This Peer-Reviewed Article is brought to you for free and open access by BYU ScholarsArchive. It has been accepted for inclusion in Faculty Publications by an authorized administrator of BYU ScholarsArchive. For more information, please contact ellen_amatangelo@byu.edu. 
Running Head: SUPPORT GROUP

An Outreach Support Group for International students

\author{
Timothy B. Smith ${ }^{1}$ \\ University of South Dakota \\ Li-Chen Chin \\ University of Pennsylvania \\ Arpana Inman \\ Jennifer Hudson \\ Temple University
}

1 Correspondence concerning this article should be addressed to Timothy B. Smith, Ph.D., USD Psychology Department, Vermillion, SD 57069. 
Abstract

International students often face challenges in adjusting to their new environment without the use of available local supports, such as counseling. Suggestions are provided for forming an outreach support group that enhances international student participation by minimizing stigma associated with mental health services and by addressing both practical and emotional issues. 
Support Groups

An Outreach Support Group for International Students

In recent years, much emphasis has been placed upon effective and appropriate multicultural counseling strategies, with the bulk of the literature focused on American racial and ethnic groups. However, many American colleges and universities also enroll large numbers of international students, individuals who are at risk for emotional difficulties related to or compounded by cultural adjustment issues (Sandhu, 1994). Despite this increased risk, international students typically underutilize campus counseling services (Brinson \& Kottler, 1995). Part of this underutilization may be explained by the fact that many international students primarily seek out informal support networks such as friends or family rather than psychological assistance (Bradley, Parr, Lan, \& Bingi, 1995). However, since many international students are separated from their customary support networks (often for the first time), alternative forms of effective and appropriate support are clearly needed.

The purpose of this paper is to present one such alternative, the organization of outreach support groups for international students. An outreach group can serve as an informal support network and can provide students the opportunity to address personal concerns in a safe, normalizing environment. The following suggested procedures for forming such a group have been found to be successful at two large northeastern universities over a two-year period.

To enhance participation by minimizing stigma associated with mental health services, support groups meet outside the counseling center in campus cultural centers, English as a Second Language (ESL) departments, or international programs offices. Close cooperation with these campus offices, which are the primary contacts for international students, is essential to the group's success.

Having another campus office sponsor the group, along with creative advertising, can overcome difficulties associated with recruiting group participants. An approach that has been found to work well is the announcement of a one hour meeting (with refreshments) on a topic such as "How to survive at X University: The international student's guide to success", "Questions about 
American culture?", "Dating in America", or "Homesick and hating hamburgers?". An electronic mail announcement of the meeting is sent to each international student's computer account (obtained from the registrar or office of international programs), flyers are posted at campus locations, notices are placed in university newspapers and websites, and staff members at the above mentioned offices are encouraged to make personal invitations to students they contact. Minimal reference to the counseling service is made (although separate announcements describing the counseling service are sent). Then, at the special topic meeting, the weekly support group is announced repeatedly at key times in the presentation. Specifically, it has been found that when meeting participants are asked what issues they would find helpful to discuss in a support group setting, they become aware that they do have issues that could be assisted by such a group. Sign up sheets with participant contact information and topic interests are collected, and handouts with the time and location of the next support group meeting are distributed. Response rates to this recruitment approach have been high.

At the initial support group meeting, customary procedures for beginning an open, semi-structured group may then be initiated. Care should be taken to follow members' lead regarding the content of focus for group meetings. Common issues have included loneliness, frustration with aspects of American culture (e.g., the education system), relationship problems, experiences of discrimination or marginalization, assertiveness difficulties, and symptoms of depression or anxiety. The group offers both practical and emotional support for these issues. Other group benefits reported by participants have included normalizing concerns, gaining insights into American culture, enhancing social networks, practicing English usage, and learning how and when to use formal mental health services. Confidential evaluation forms have helped group facilitators better tailor the group to members' unspoken needs.

Group facilitators should be guided by existing standards of multicultural sensitivity and competence (Bradley, Parr, Lan, \& Bingi, 1995; Brinson \& Kottler, 1995; Sandhu, 1994). Facilitators should be open about their 
affiliation with counseling services; however, the optimal facilitator role minimizes professional distance and psychological terminology. Therapeutic techniques (e.g., self-disclosure, reframing) that blend naturally with the group's focus may be used, but the use of scripted or in-depth emotional exercises is not advised.

Due to some culture's perceptions of gender roles, it has been found maximally useful to have two group facilitators, one of either sex. Thus, group members who are either intimidated by or disrespectful of one gender are more likely to remain active in the group. Group member participation may be enhanced by having at least one international staff co-facilitator (from the office of international programs, ESL department, or one of the campus cultural centers) who can provide important first-hand validation of adjustment struggles as well as information on coping methods and practical resources (such as connecting with "host families").

Evaluations of the group by participants can serve to refine plans for subsequent groups. Evaluations of outreach groups run by the authors over two years have been overwhelmingly positive (100\% of participants have rated the group highly), but complaints about meeting times or insufficient coverage of all issues pertinent to the individual have occurred among a minority of group members. Furthermore, group membership has fluctuated, with approximately 75\% of initial participants attending regularly. Additional monitoring of long-term outcomes and retention initiatives is required.

In summary, an outreach support group for international students demonstrates counselors' commitment to reaching underserved populations. By holding the group outside a counseling center, stigma associated with mental health services is minimized. By involving non-counselors from associated campus offices, member participation and the practical utility of the group are enhanced. Our past efforts with similar groups hosted exclusively by counseling centers have recruited far fewer (and more acculturated) students. Thus, while refinements to the suggestions presented here may be needed, present experience supports this culture-centered initiative as an effective outreach intervention. 
References

Bradley, L. J., Parr, G., Lan, W. Y., \& Bingi, R. (1995). Counseling

expectations of international students. International Journal for the

Advancement of Counselling, 18(1), 21-31.

Brinson, J. A., \& Kottler, J. (1995). International students in

counseling: Some alternative models. Journal of College Student Psychotherapy,

$\underline{9}(3), 57-70$.

Sandhu, D. A. (1994). An examination of the psychological needs of

international students: Implications for counselling and psychotherapy.

International Journal for the Advancement of Counselling, 17, 229-239. 